\title{
Investigation of the Influence of Ni Doping on the Structure and Hardness of Ti-Ni-C Coatings
}

\author{
J. Daniel, P. Souček, K. Bernátová, L. Zábranský, M. Stupavská, V. Buršíková, and P. Vašina \\ Department of Physical Electronics, Faculty of Science, Masaryk University, Kotlarska 2, 61137 Brno, Czech Republic \\ Correspondence should be addressed to P. Vašina; vasina@physics.muni.cz
}

Received 31 January 2017; Revised 16 April 2017; Accepted 30 May 2017; Published 6 July 2017

Academic Editor: Albano Cavaleiro

Copyright (C) 2017 J. Daniel et al. This is an open access article distributed under the Creative Commons Attribution License, which permits unrestricted use, distribution, and reproduction in any medium, provided the original work is properly cited.

\begin{abstract}
Nanocomposite nc-TiC/a-C:H thin films exhibit unique combination of mechanical properties, high hardness, low friction, and wear. Selective doping by weak-carbide forming element can be used in order to specifically design the physical and chemical properties of nc-TiC/a-C:H coatings. In this paper we report on an effect of nickel addition on structure and hardness of the ncTiC/a-C:H coatings. The effect of Ni alloying on the coating structure under conditions of DCMS and HiPIMS depositions was studied. The coating structure was correlated with the coating hardness. The grain size, the grain carbon vacancy concentration, and the mean grain separation were found to be the key parameters determining the coating hardness. Ni doping proved to have a significant effect on the coating microstructure which resulted in changes of the hardness of the deposited coatings.
\end{abstract}

\section{Introduction}

Nanocomposite transition metal carbide based coating systems have been systematically studied because of advantageous combination of their physical, chemical, and mechanical properties such as high hardness, high wear resistance, low friction coefficient, and good thermal stability. This nanocomposite structure consists of hard nanocrystalline metal carbide grains surrounded by amorphous carbon phase. One of the most widely studied transition metal carbide nanocomposite systems, denoted as nc-TiC/a-C:H, consists of nanocrystalline $\mathrm{TiC}$ grains embedded in an amorphous hydrogenated carbon matrix [1]. The nc-TiC/a-C:H coatings with high hardness [2-15] or with low coefficient of friction and wear [16-19] were described in the literature. The synthesis of hydrogenated nc-TiC/a-C:H nanocomposites is generally performed utilizing a hybrid PVD-PECVD process of sputtering of titanium target in hydrocarbon containing plasma. This process was described in detail in [20].

To further enhance the mechanical properties of titanium and carbon based coatings, a strategy utilizing doping of the coatings by a non-carbine forming element such as nickel was proposed [21]. If nickel is introduced in specific quantities under specific deposition conditions, nickel can be incorporated into the $\mathrm{Ti}-\mathrm{C}$ grains and therefore metastable $\mathrm{Ti}-\mathrm{Ni}$ $\mathrm{C}$ grains embedded in carbon matrix can be formed [22]. It was calculated that $\mathrm{Ti}-\mathrm{Ni}-\mathrm{C} / \mathrm{a}-\mathrm{C}$ system with $\gtrsim 25 \%$ of $\mathrm{Ni}$ can transit to a more thermodynamically favorable state: the metastable grains will release carbon to the amorphous phase. This effect can result in changes of the coatings structure and thus in their mechanical properties [22]. Jansson et al. prepared nanocomposite $\mathrm{Ti}-\mathrm{Ni}-\mathrm{C}$ coatings with constant $[\mathrm{Ni}] /[\mathrm{Ti}]$ ratio and different carbon contents by DC cosputtering of $\mathrm{Ti}, \mathrm{C}$, and $\mathrm{Ni}$ targets and compared them with nickel-free nc-TiC/a-C coatings prepared using the same deposition techniques [22]. Addition of $\sim 25$ at. \% of $\mathrm{Ni}$ led to the grain size decrease and increase of the amount of the amorphous carbon phase. Also, a moderate hardening of the coatings was observed. This effect was attributed to the nanocomposite hardening effect described by Zehnder et al. [3, 12]. Furthermore, if the Ti-Ni-C system contains $<25$ at. $\%$ of $\mathrm{Ni}$, application of external forces, for example, via indentation of friction, can lead to overcoming the thermodynamical barrier and releasing of carbon from the grain to the matrix. Therefore, nc-Ti-Ni-C/a-C:H system could be used as a smart lubricating coating. 
In this work hybrid PVD-PECVD process consisting of sputtering of a metallic target in reactive hydrocarbon atmosphere $[4,23-26]$ is used to synthesize nanocomposite hydrogenated nc-Ti-Ni-C/a-C:H coatings. The hybrid process instead of cosputtering was used to further expand the concept proposed for hydrogen free coatings [22]. Also, the hybrid process has a better future applicability as it is already industrially used [23] exhibiting higher deposition rates. Significantly lower amounts of Ni (less than $\sim 10$ at. \%) than in the case of Jansson et al. [22] were used to purposely synthesize coatings with metastable $\mathrm{Ti}-\mathrm{Ni}-\mathrm{C}$ grains. To study the influence of the plasma excitation on the possibilities of synthesis of the metastable grains, Direct Current Magnetron Sputtering (DCMS) and High Power Impulse Magnetron Sputtering (HiPIMS) processes were used. HiPIMS process is characterized by enhanced adatom diffusion, enhanced ion and energy fluxes, and higher thin film forming ion concentration compared to DCMS [26-28]. The influence of $\mathrm{Ni}$ doping on the chemical composition, phase composition, microstructure, and mechanical properties of nc-Ti-Ni-C/a$\mathrm{C}: \mathrm{H}$ coatings prepared by both DCMS and HiPIMS will be discussed.

\section{Experimental Details}

Samples were deposited in a semi-industrial Alcatel SCM 650 sputtering system. Sputtering target $(\varnothing 20 \mathrm{~cm})$ was driven by a Hüttinger TruPlasma Bipolar 4010 generator operated in DC mode in the DCMS case or by Melec SIPP 2000 generator in the HiPIMS case. A well balanced magnetic field configuration was used; for more details of the magnetic field configuration see [4]. The substrates were mounted onto a biasable (13.56 MHz RF) substrate holder $6.5 \mathrm{~cm}$ above the racetrack of the target. Titanium target with purity of 99.7\% was used for preparation of the Ni-free samples. A compound target with $87.5 \%$ of $\mathrm{Ti}$ and $12.5 \%$ of $\mathrm{Ni}$ and purity of $99.95 \%$ was used for the Ni-doped coating preparation. The deposition chamber was evacuated by a turbomolecular pump backed by a Roots pump to the base pressure in the order of $10^{-4} \mathrm{~Pa}$. Gas inlet was located between the substrate holder and the target at the distance of $2 \mathrm{~cm}$ from the target. Acetylene with purity of $99.6 \%$ was used as a source of carbon and hydrogen; argon with purity of $99.999 \%$ was used as a buffer gas. Gases were dosed via mass-flow controllers.

Cemented tungsten-carbide substrates $\left(R_{a}=3 \mathrm{~nm}\right)$ were precleaned in a chemical bath and ultrasonicated in a degreasing agent. Both the target and the substrates were further cleaned by Ar ion bombardment. During this cleaning phase, the substrate was preheated prior to the deposition to a temperature of $\sim 150^{\circ} \mathrm{C}$. After the cleaning phase, the argon flow rate was set to $20 \mathrm{sccm}(\sim 1.1 \mathrm{~Pa})$ and the deposition of $\sim 750 \mathrm{~nm}$ thick adhesion interlayer took place. Then the acetylene was introduced into the chamber. The coating's depositions were performed with deposition parameters summarized in Table 1. Longer deposition time in HiPIMS was used due to generally lower deposition rates [29]. For DCMS depositions the bias of $-100 \mathrm{~V}$ was used; for HiPIMS deposition a substrate was left on floating potential. Substrate temperature of $\sim 300^{\circ} \mathrm{C}$ was reached in both the DCMS and
TABLE 1: Parameters of the coatings deposition.

\begin{tabular}{lcc}
\hline & DCMS & HiPIMS \\
\hline Mean power $(\mathrm{kW})$ & 1.25 & 1.25 \\
Pulse length $(\mu \mathrm{s})$ & - & 400 \\
Pulse frequency $(\mathrm{Hz})$ & - & 30 \\
Maximal current $(\mathrm{A})$ & $\sim 2.5$ & $\sim 400$ \\
Substrate bias $(\mathrm{V})$ & -100 & - \\
Argon flow rate $(\mathrm{sccm})$ & 20 & 20 \\
Deposition duration $(\mathrm{min})$ & 60 & 120 \\
\hline
\end{tabular}

the HiPIMS cases after approximately 15 minutes from the start of the deposition. After the deposition the samples were left to cool down for two hours under vacuum.

Spherical abrasions prepared by a calotester and measured by laser confocal microscope LEXT OLS4000 3D were used for determination of coating's thickness. Energydispersive X-ray spectroscopy (EDX) analyses using Tescan MIRA FEG SEM equipped with an EDX detector from Oxford Instruments were performed to determine the chemical composition of the coatings. Internal library of standards included in the Aztec software by Oxford Instruments was used for quantitative evaluation of the composition. Xray diffraction (XRD) utilizing Rigaku SmartLab Type F diffractometer was used to determine the mean grain size and the lattice parameter. The diffractometer operated with $\mathrm{Cu}_{\mathrm{K} \alpha}$ radiation $(\lambda=0.1541 \mathrm{~nm})$. Grazing angle of incidence (GIXRD) configuration with the angle of $0.5^{\circ}$ was used for the measurement. X-ray photoelectron spectroscopy (XPS) was used to obtain information about the phase composition: content of the amorphous phase and the nanocrystalline phase. The XPS signals were recorded using a Thermo Fischer Scientific K-Alpha XPS. This system equipped with a microfocused monochromatic $\mathrm{Al}_{\mathrm{K} \alpha} \mathrm{X}$-ray source $(1486.6 \mathrm{eV})$ was used for determination of phase composition of coatings. An X-ray beam with $200 \mathrm{~W}$ power (650 microns spot size) was used for determination of the lattice parameter as well as the mean grain size. The mean size of the $\mathrm{TiC}$ grains was calculated from the most intensive diffractogram peak corresponding to the (111) crystallographic direction using the Scherrer equation neglecting the effect of the grain strain [30]. The lattice parameter was always calculated from the three first intensive TiC diffraction peaks: (111), (200), and (311). Survey and high resolution spectra were collected with pass energy of 50 and $20 \mathrm{eV}$, respectively. The charge shift of the spectra was then corrected by setting the $\mathrm{C} 1 \mathrm{~s}$ peak to $284.8 \mathrm{eV}$. Fischerscope H100 depth sensing indenter (DSI) equipped with a Berkovich tip was used to measure the coating's hardness. The load applied on the tip and the corresponding indentation depths were recorded simultaneously for both the loading and the unloading parts. Hardness was determined using standard Oliver and Pharr method [31]. The indentation load of $40 \mathrm{mN}$ was chosen in order to keep the radius of the deformed volume (estimated according to Johnson's contact model [32]) sufficiently low to avoid influence of the substrate. The tip area function was calibrated using fused silica and hard metal standards. 
Typically, 32 indents were performed in different places on the sample for hardness analysis.

Stoichiometry of TiC grains was calculated in a simplified qualitative model, where all titanium atoms are assumed to be forming $\mathrm{Ti}-\mathrm{C}$ bonds in the titanium carbide grains. Coefficient of stoichiometry of $\mathrm{TiC}$ grains in the $\mathrm{Ni}$-free coatings was calculated as

$$
x=\frac{[\mathrm{C}] \cdot A_{\mathrm{C}-\mathrm{Ti}}}{[\mathrm{Ti}] \cdot A_{\mathrm{C} 1 \mathrm{~s}}}
$$

where [C] and [Ti] denote the atomic composition of the sample taken from EDX, $A_{\mathrm{C}-\mathrm{Ti}}$ denotes the area under $\left(\mathrm{C}-\mathrm{Ti}+\mathrm{C}-\mathrm{Ti}^{*}\right)$ peak, and $A_{\mathrm{Cls}}$ denotes the area of the whole XPS C1s peak [26]. Two extreme cases were calculated. The first case assumed that there were no $\mathrm{Ni}-\mathrm{C}$ bonds in the grain. In this case the coefficient of stoichiometry could be calculated directly from (1). The second case assumed that all the titanium as well as the nickel atoms created bonds with $\mathrm{C}$ atoms. In this case the coefficient of stoichiometry was calculated using a modification of (1):

$$
x=\frac{[\mathrm{C}] \cdot\left(A_{\mathrm{C}-\mathrm{Ti}}+A_{\mathrm{C}-\mathrm{Ni}}\right)}{([\mathrm{Ti}]+[\mathrm{Ni}]) \cdot A_{\mathrm{Cls}}},
$$

where $A_{\mathrm{C}-\mathrm{Ni}}$ denotes area under $(\mathrm{C}-\mathrm{Ni})$ peak in XPS $\mathrm{Cls}$ spectrum. The actual coefficient of stoichiometry should therefore lie between those of the extreme cases.

The mean grain separation (MGS) was calculated using information about the chemical composition, the mean grain size, and the phase composition. For calculation of the MGS a model assuming cubic grains uniformly distributed in the matrix was utilized $[12,21]$. The equation used for calculation of the nc-TiC/a-C mean grain separation was adopted from [21] and adapted for $\mathrm{nc}-(\mathrm{Ti}, \mathrm{Ni}) \mathrm{C} / \mathrm{a}-\mathrm{C}: \mathrm{H}$ coatings assuming that $\mathrm{Ni}$ is included in $\mathrm{TiC}$ grains not forming regular carbide:

$$
\begin{aligned}
\text { MGS } & =c\left(\sqrt[3]{1+r_{\mathrm{vol}}}-1\right), \\
r_{\mathrm{vol}} & =\frac{A_{\mathrm{C}-\mathrm{C}}}{A_{\mathrm{C}-\mathrm{Ti}}+A_{\mathrm{C}-\mathrm{Ni}}} \frac{M_{\mathrm{a}-\mathrm{C}}}{x M_{\mathrm{TiC}}+y M_{\mathrm{Ni}}} \frac{x \rho_{\mathrm{TiC}}+y \rho_{\mathrm{Ni}}}{\rho_{\mathrm{a}-\mathrm{C}}},
\end{aligned}
$$

where $c$ denotes the mean grain size, $A_{\mathrm{C}-\mathrm{C}}, A_{\mathrm{C}-\mathrm{Ti}}$, and $A_{\mathrm{C}-\mathrm{Ni}}$ denote areas under $(\mathrm{C}-\mathrm{C}),\left(\mathrm{C}-\mathrm{Ti}+\mathrm{C}-\mathrm{Ti}^{*}\right)$, and $(\mathrm{C}-\mathrm{Ni})$ peaks in XPS C1s spectrum, $M_{\mathrm{a}-\mathrm{C}}, M_{\mathrm{TiC}}$, and $M_{\mathrm{Ni}}$ denote atomic weights of amorphous carbon, titanium carbide, and nickel, and $\rho_{\mathrm{a}-\mathrm{C}}, \rho_{\mathrm{TiC}}$, and $\rho_{\mathrm{Ni}}$ denote mass densities of amorphous carbon, titanium carbide, and nickel. The atomic weights were taken as $M_{\mathrm{a}-\mathrm{C}}=12.0 \mathrm{amu}$ [12], $M_{\mathrm{TiC}}=59.5 \mathrm{amu}$ [12], and $M_{\mathrm{Ni}}=58.7 \mathrm{amu}$ [33]. Mass densities $\rho_{\mathrm{a}-\mathrm{C}}=2.20 \mathrm{~g} \cdot \mathrm{cm}^{-3}$ [12], $\rho_{\mathrm{TiC}}=4.91 \mathrm{~g} \cdot \mathrm{cm}^{-3}[12]$, and $\rho_{\mathrm{Ni}}=8.91 \mathrm{~g} \cdot \mathrm{cm}^{-3}$ [34] were used. Symbols $x$ and $y$ in (4) denote the weighted average of titanium and nickel content:

$$
\begin{aligned}
& x=\frac{[\mathrm{Ti}]}{[\mathrm{Ti}]+[\mathrm{Ni}]}, \\
& y=\frac{[\mathrm{Ni}]}{[\mathrm{Ti}]+[\mathrm{Ni}]},
\end{aligned}
$$

where [Ti] and [Ni] denote content of titanium and nickel in the coating.

\section{Results}

Series of Ni-free nc-TiC/a-C:H as well as Ni-doped nc- $(\mathrm{Ti}$, $\mathrm{Ni}$ )C/a-C:H coatings were prepared by HiPIMS and DCMS processes. The thickness of the DCMS prepared coatings was in the range of $3.8-4.2 \mu \mathrm{m}$ for coatings with $\sim 30 \%-\sim 70 \%$ of carbon. The thickness of the HiPIMS prepared coatings deposited for twice as long as the DCMS deposited coatings was in the range of $2.5-3.0 \mu \mathrm{m}$ for coatings with $\sim 20 \%-\sim 75 \%$ of carbon. Deposition rate of the DCMS prepared coatings was thus approximately three times higher than the deposition rate of HiPIMS prepared coatings. This agrees well with finding that the deposition rate is generally significantly lower in HiPIMS compared to DCMS, mostly due to the titanium ion back-attraction to the target $[27,29,35]$. No influence of nickel addition on coating's thickness and deposition rate was observed.

As the total carbon content in the $\mathrm{Ni}$-free as well as the $\mathrm{Ni}$ doped coating increased, a total content of metallic elements, that is, $\mathrm{Ti}$ in the Ni-free coatings and $\mathrm{Ti}$ and $\mathrm{Ni}$ in the $\mathrm{Ni}$ doped coatings, linearly decreased. Figure 1 shows linear decrease of the total content of titanium and nickel in the case of the Ni-doped coatings prepared by DCMS (Figure 1(a)) and HiPIMS (Figure 1(b)).

An example of diffraction patterns of the $\mathrm{Ni}$-free coating with $[\mathrm{C}] /[\mathrm{Ti}]$ ratio of $\sim 0.33$ (black line) and the coating containing $\sim 10 \% \mathrm{Ni}$ with the same $[\mathrm{C}] /[\mathrm{Ti}]$ ratio (red line) is depicted in Figure 2. Only peaks corresponding to the $\mathrm{TiC}$ phase were observed in the diffraction pattern; no diffraction peaks corresponding to nickel or titanium phase were observed. The same, that is, only peaks corresponding to the $\mathrm{TiC}$ phase, were observed in case of all studied coatings. The lattice parameter calculated from the most intense peak of Xray diffractograms is plotted in Figure 3. The bulk TiC lattice parameter of $4.33 \AA$ [36] is plotted as a horizontal line for comparison. Figure 3(a) shows the comparison of the lattice parameter of the $\mathrm{Ni}$-free and the $\mathrm{Ni}$-doped coatings prepared by the DCMS; Figure 3(b) shows the same comparison in the HiPIMS case. The lattice parameter increased with increasing carbon content for all the coatings with less than $\sim 50 \%$ of C. This was followed by a decrease of the lattice parameter for the DCMS and the Ni-free HiPIMS coatings. The Ni-doped HiPIMS deposited coatings with carbon content $\gtrsim 50 \%$ exhibited lattice parameter independent of the total carbon content. The HiPIMS prepared coatings always exhibited lattice parameter lower than the DCMS prepared coatings and also lower than lattice parameter of bulk TiC. The lattice parameter of the Ni-doped coatings with $\leq 50 \% \mathrm{C}$ was always higher than the lattice parameter of the corresponding Ni-free coatings.

The comparison of the mean grain size of the Ni-free and the Ni-doped coatings prepared by DCMS is shown in Figure 4(a). The mean grain size of the Ni-free coatings did not significantly change with increasing total carbon content up to $\sim 50 \%$ and was $\sim 25 \mathrm{~nm}$. Ni-doped coatings exhibited pronounced increase of the grain size from $\sim 5 \mathrm{~nm}$ to $\sim 24 \mathrm{~nm}$ as the carbon content increased from $\sim 30 \%$ to $~ 50 \%$. As the carbon content increased further, the grain size decreased both for the $\mathrm{Ni}$-free and for the $\mathrm{Ni}$-doped coatings and 


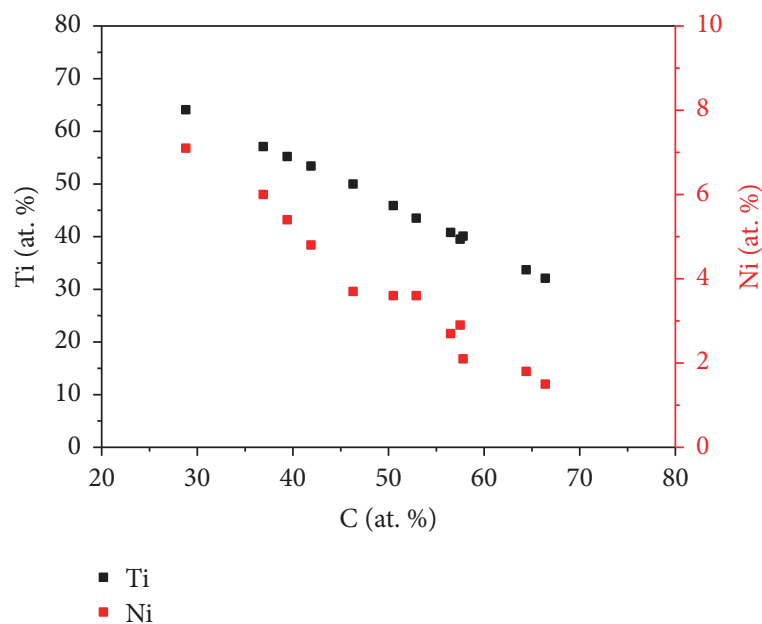

(a)

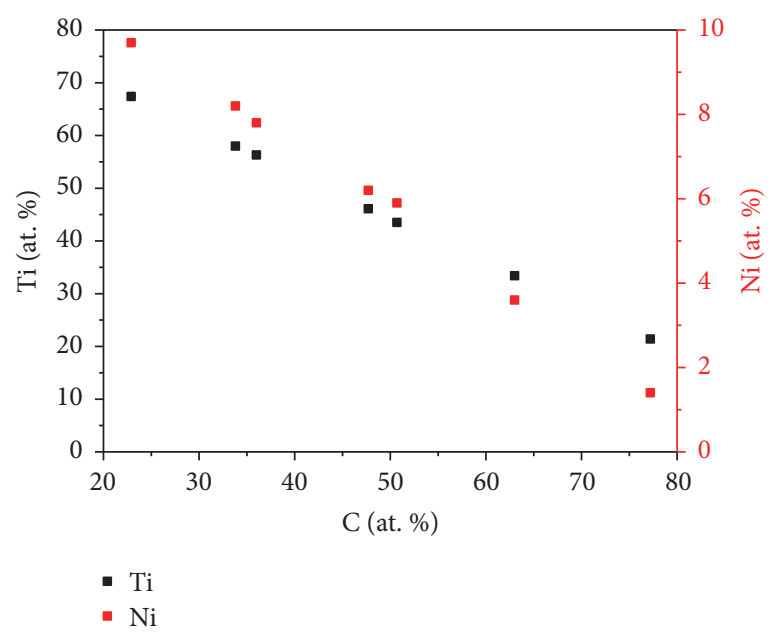

(b)

Figure 1: Dependence of titanium and nickel content on the total content of carbon. Comparison of (a) the DCMS and (b) the HiPIMS prepared coatings.

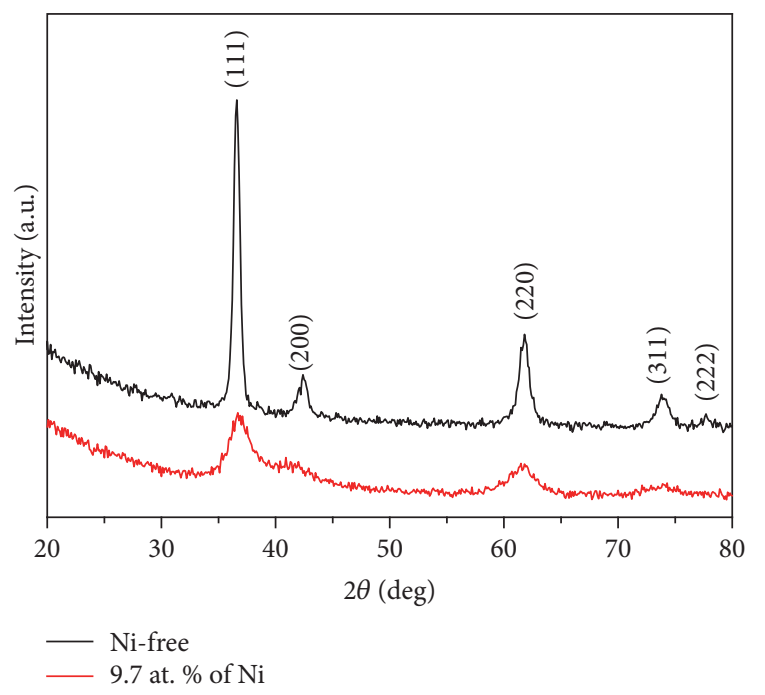

FIGURE 2: Diffraction patterns of the HiPIMS prepared Ni-free (black line) coating with $[\mathrm{C}] /[\mathrm{Ti}]$ ratio $\sim 0.33$ and the HiPIMS prepared $\mathrm{Ni}$-doped coating with $9.7 \%$ of $\mathrm{Ni}$ (red line) with $[\mathrm{C}] /[\mathrm{Ti}]$ ratio $\sim 0.34$. Crystallographic direction of the TiC peaks is denoted above certain peaks.

the coating with the highest amount of carbon exhibited grain size of $\sim 4 \mathrm{~nm}$. The mean grain size of the HiPIMS prepared coatings is plotted in Figure 4(b). The mean grain size in the Ni-free coatings decreased with the increasing total carbon content from $\sim 37 \mathrm{~nm}$ for coating with $\sim 25 \%$ of carbon down to $\sim 5 \mathrm{~nm}$ for coating with $\sim 68 \%$ of carbon. The grain size in the Ni-doped coatings increased from $\sim 4 \mathrm{~nm}$ for coating with the lowest amount of carbon up to $\sim 15 \mathrm{~nm}$ for coating with carbon amount of $\sim 48 \%$. As the carbon content increased further, the grain size decreased down to $\sim 2 \mathrm{~nm}$ and remained constant for the rest of the carbon rich coatings. Ni-doped coatings showed generally smaller grains compared to Ni-free coatings which was more pronounced in the HiPIMS series. The grain size reduction effect was also more pronounced in coatings with low amount of carbon.

High resolution XPS measurements were carried out on the C1s, Ti2p, and Ni2p peak regions. Comparison of Ti2p peaks of coatings with similar carbon content without and with Ni prepared at both the DCMS and HiPIMS is plotted in Figure 5. Samples with the lowest amount of carbon and thus the highest amount of nickel are shown to illustrate the highest possible effect of $\mathrm{Ni}$ doping on the measures Ti2p peaks. The Ti2p peaks exhibit minimal differences between the samples. The binding energy of the maximum intensity of the Ti2 $\mathrm{p}_{3 / 2}$ of $449.6-449.9 \mathrm{eV}$ as well as that of the Ti2 $\mathrm{p}_{1 / 2}$ peak of $460.9-461.3 \mathrm{eV}$ agrees with the position of the Ti$\mathrm{C}$ bond $[3,10,37]$ indicating majority of Ti being bonded to carbon. Ti-O bonding is also present in the coating as a minor component. No Ti-Ti bonding was detected. This was true for all of the analyzed samples independently of their carbon content, nickel presence, or the method of deposition. The Ni2p peaks of the DCMS and HiPIMS deposited coatings with the highest amount of nickel together with a reference spectrum $\mathrm{Ni}$ (99.999\% purity, Goodfellow) are presented in Figure 6. The positions of the Ni2 $\mathrm{p}_{3 / 2}$ as well as the Ni2 $\mathrm{p}_{1 / 2}$ peaks in the deposited coatings are shifted by $0.8 \mathrm{eV}$ to higher energies compared to the Ni reference. The positions of the $\mathrm{Ni} 2 \mathrm{p}$ peaks are in good agreement with the literature value for Ni-C bonds [37]. Further, no Ni-Ni bonds were detected, which was in good agreement with findings from XRD showing no presence of Ni crystallites. The amount of the $\mathrm{a}-\mathrm{C}: \mathrm{H}$ phase was quantified using the curve deconvolution of the C1s peak $[15,22,37]$. An example of deconvoluted high resolution Cls peak of $\mathrm{Ni}$-free ( $\sim 61 \%$ of carbon) and Ni-doped ( $\sim 58 \%$ of carbon) coatings prepared by DCMS is shown in Figure 7. An amount of the a-C:H phase was estimated by comparison of $\mathrm{C}-\mathrm{C}$ bond area to sum of $\mathrm{C}-\mathrm{Ti}$, $\mathrm{C}-\mathrm{Ti}^{*}$ and $\mathrm{C}-\mathrm{Ni}$ bond areas. 


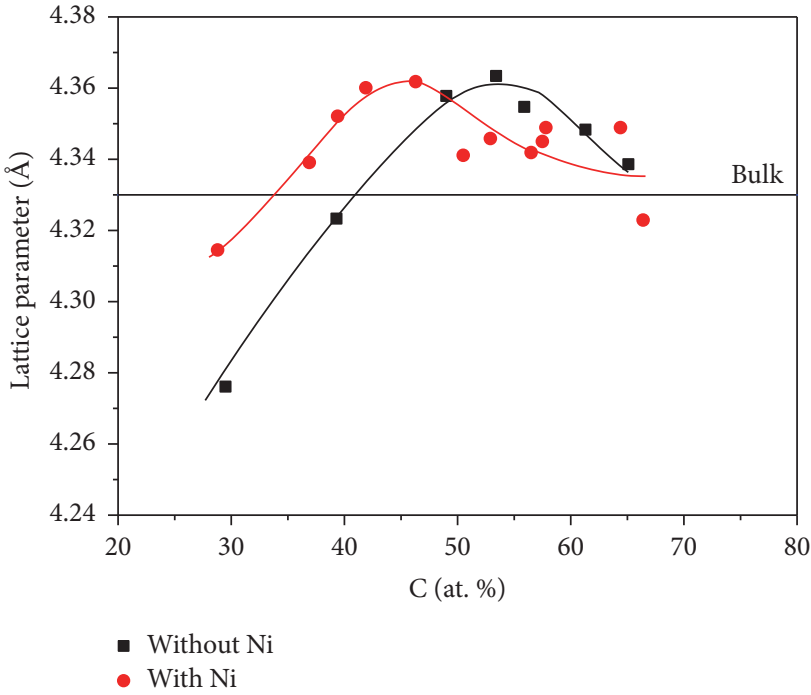

(a)

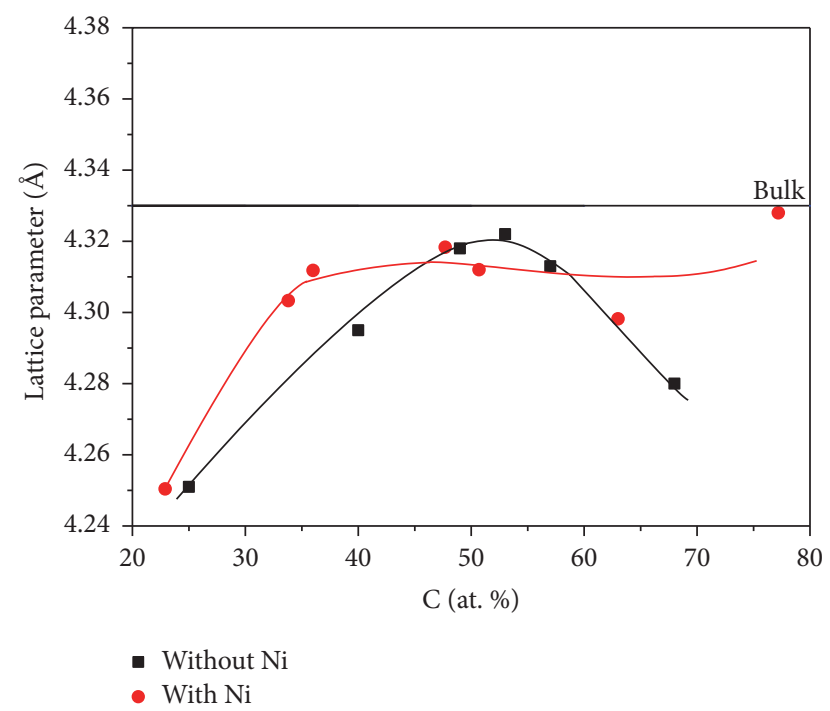

(b)

FIgURE 3: The lattice parameter of the Ni-free (black marks) and the Ni-doped (red marks) coatings. Comparison of (a) the DCMS prepared coatings with (b) the HiPIMS prepared coatings. Line at $4.33 \AA$ A denoted the bulk TiC lattice parameter [36]. Lines are added as guides for the eye.

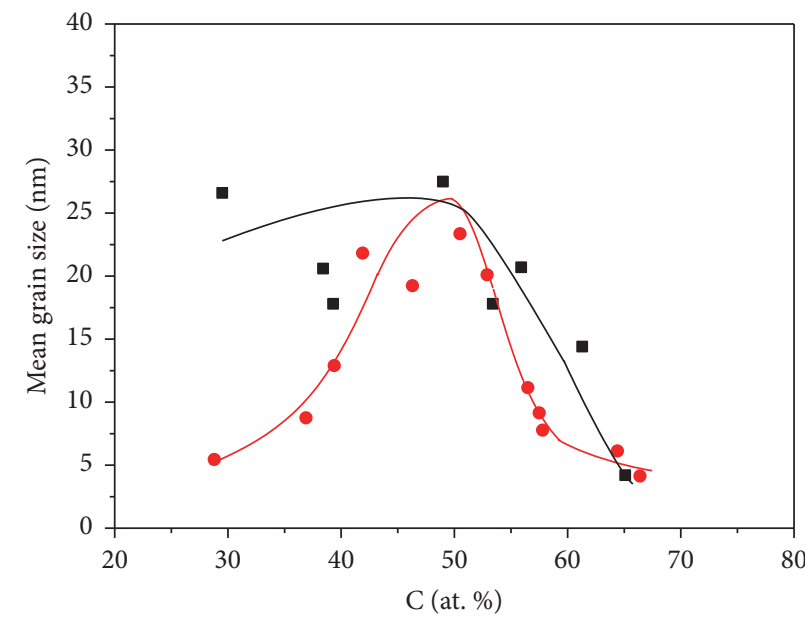

- Without Ni

- With Ni

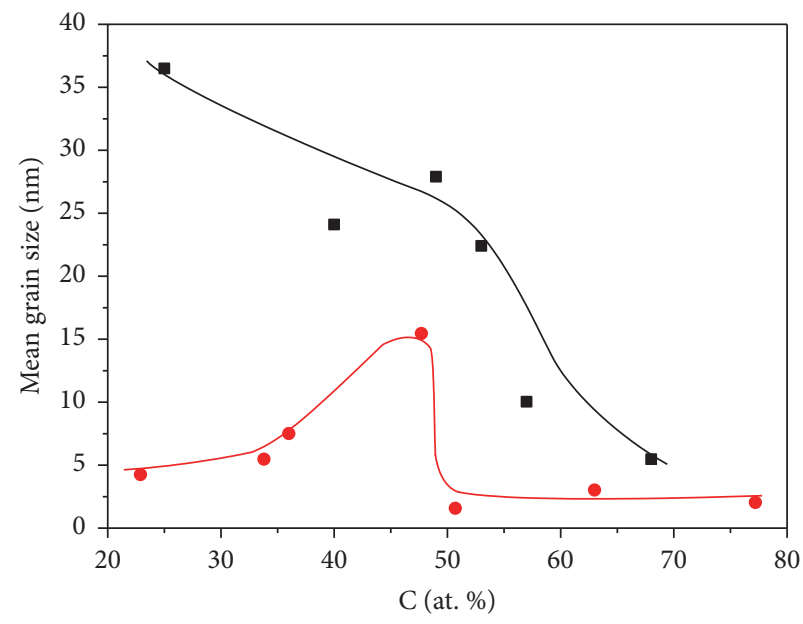

- Without Ni

- With $\mathrm{Ni}$

(a)

(b)

FIGURE 4: The mean grain size of the Ni-free (black marks) coatings compared with the Ni-doped (red marks) coatings. Comparison of (a) the DCMS prepared coatings and (b) the HiPIMS prepared coatings. Lines are added as guides for the eye.

Figures $8(\mathrm{a})$ and $8(\mathrm{~b})$ show the comparison of the amount of the a-C:H phase of the $\mathrm{Ni}$-free and the $\mathrm{Ni}$-doped coatings prepared by DCMS and HiPIMS, respectively. Rapid increase of amount of the a-C:H phase was observed in the DCMS deposited coatings. However, the $\mathrm{Ni}$-free coatings with $\$ 50 \%$ exhibited significantly higher amount of the a-C:H phase compared to corresponding Ni-doped coatings. This effect is the most pronounced in the coatings with the lowest amount of carbon where the Ni-free coatings exhibited significantly higher amount of the a-C:H phase than the $\mathrm{Ni}$ doped coatings. No effect of $\mathrm{Ni}$ addition on the total a-C:H amount was observed in the HiPIMS deposited coatings. Both the Ni-free and the Ni-doped coatings exhibited slight increase of the amount of the a-C:H phase in the coatings with total carbon content $\leqslant 50 \%$ followed by rapid increase up to $\sim 70 \%$ for coatings with the high amount of carbon.

Coefficient of stoichiometry in the DCMS prepared coatings is plotted in Figure 9(a). The Ni-free coatings with 


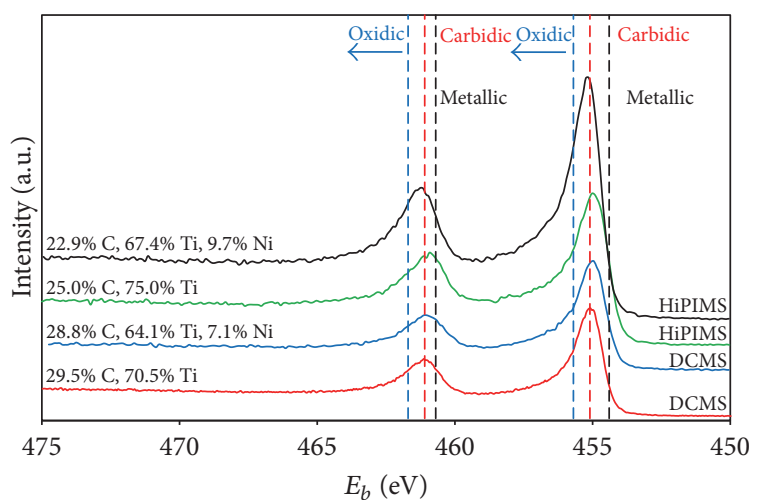

FIgURE 5: Comparison of high resolution XPS spectra of the Ti2p peaks.

carbon content $\leqslant 50 \%$ exhibited increase of coefficient of stoichiometry with increasing carbon content. When $\$ 50 \%$ of carbon was reached, coefficient of stoichiometry of $\sim 1$ was attained. As the carbon content increased further, the coefficient of stoichiometry decreased. In the case of the Nidoped coatings the stoichiometry coefficient was calculated for two extreme cases. In both cases the Ni-doped coatings exhibited a monotonous increase of the coefficient of stoichiometry with increasing carbon content; stoichiometry coefficient $\sim 1$ was reached for coatings with $\gtrsim 60 \%$ of carbon. The coefficient of stoichiometry was higher for the Ni-doped coatings with $\leqslant 45 \%$ of carbon. The Ni-doped coatings with carbon content of $\sim 45-65 \%$ exhibited lower coefficient of stoichiometry, as the increase of the coefficient of stoichiometry was slower than in the case of the $\mathrm{Ni}$-free coatings. The coefficient of stoichiometry of the Ni-doped coatings was higher for coatings with carbon content $\gtrsim 60 \%$ as the Nifree coatings already exhibited a decrease of the coefficient of stoichiometry. Coefficient of stoichiometry in the $\mathrm{Ni}$ free coatings prepared by HiPIMS (see Figure 9(b)) with $\$ 50 \%$ of $\mathrm{C}$ also increased with increasing carbon content. Similarly to the DCMS case, the HiPIMS coatings with 50\% of $\mathrm{C}$ exhibited coefficient of stoichiometry $\sim 1$. The Ni-doped coatings with $\leqslant 50 \%$ of carbon exhibited increasing of the stoichiometry coefficient with increasing carbon content. The coefficient of stoichiometry in the Ni-doped coatings reached maximum value $\sim 1$ for coatings with $50-60 \%$ of carbon and it decreased with further carbon content increase. The coefficient of stoichiometry was lower for the HiPIMS deposited Ni-doped coatings with $\leqslant 50 \%$ of carbon.

The mean grain separation is plotted in Figure 10. The number of carbon monolayers separating the grains corresponding to the calculated MGS is plotted on the right axis in case of both graphs [38]. Increase of the MGS with increasing carbon content was observed in all series of coatings. This increase is, however, for coating with carbon content $\gtrsim 50 \%$ less pronounced than the increase of the amount of a-C:H phase because of simultaneous decrease of the grain size. The DCMS prepared Ni-free coatings exhibited higher MGS compared to corresponding Ni-doped coatings (see Figure 10(a)). The most pronounced difference of the MGS was observed in coatings with the lowest amount of carbon. While MGS

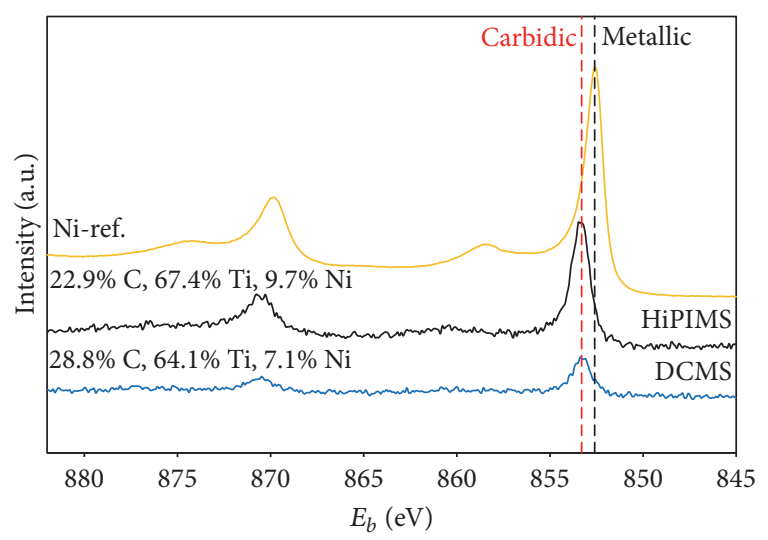

FIGURE 6: Comparison of high resolution XPS spectra of the Ni2p peaks.

of the Ni-free coating was $\sim 0.8 \mathrm{~nm}$, which corresponded to $\sim 6$ carbon monolayers, grains in the Ni-doped coating were separated only by 1 carbon monolayer which corresponded to $M G S \leqslant 0.1 \mathrm{~nm}$. As the carbon content increased the difference in MGS of the Ni-doped and the Ni-free coatings decreased. In the case of the HiPIMS prepared coatings (Figure 10(b)), the Ni-doped coatings exhibited lower MGS than the corresponding Ni-free coatings. Employing the HiPIMS, the MGS was reduced compared to DCMS which was the most pronounced particularly for $\mathrm{Ni}$-free coatings at low carbon contents.

Figure 11 shows the hardness of the DCMS (Figure 11(a)) and the HiPIMS (Figure 11(b)) prepared coatings. In the DCMS case the hardness of the Ni-free coatings increased from $\sim 11 \mathrm{GPa}$ up to $\sim 30 \mathrm{GPa}$ with increasing content of carbon up to $\sim 55 \%$. As the carbon content increased further, the hardness of the Ni-free coatings decreased. Hardness of the Ni-doped coatings increased from $\sim 20 \mathrm{GPa}$ up to $\sim 29 \mathrm{GPa}$ with increasing total carbon content up to $\sim 45 \%$. Then the hardness was not significantly influenced by the total carbon content and remained $\sim 25 \mathrm{GPa}$ for coatings with $z 45 \%$ of carbon. The Ni-free coatings prepared by HiPIMS exhibited increase of hardness from $\sim 15 \mathrm{GPa}$ up to $\sim 45 \mathrm{GPa}$ with increasing content of carbon up to $\sim 57 \%$. The hardness decreased down to $30 \mathrm{GPa}$ with further carbon increase up to $70 \%$. Hardness of the Ni-doped coatings prepared by HiPIMS behaved similarly to the case of the Ni-free up to $\sim 48 \%$ of carbon where the Ni-doped coatings exhibited maximum hardness of $\sim 38 \mathrm{GPa}$. The hardness then decreased with increasing carbon content down to $20 \mathrm{GPa}$ for coatings with $75 \%$ of carbon. HiPIMS prepared coatings exhibited higher hardness than the DCMS prepared coatings for both $\mathrm{Ni}$-free and Ni-doped coatings. The maxima of the hardness for HiPIMS prepared coatings were shifted to lower amount of carbon for Ni-doped coatings with respect to the $\mathrm{Ni}$-free case.

All the results presented in previous chapter are summarized in Table 2 (DCMS prepared coatings) and Table 3 (HiPIMS prepared coatings). Some parameters could not be determined due to problems, for example, coating delamination. Visibly erroneous data was discarded. 
TABLE 2: Overview of the coatings prepared by DCMS.

\begin{tabular}{|c|c|c|c|c|c|}
\hline $\mathrm{C}$ (at. \%) & Lattice parameter $(\AA)$ & Grain size (nm) & a-C:H phase (\%) & MGS (nm) & Hardness $(\mathrm{GPa})$ \\
\hline \multicolumn{6}{|l|}{ Ni-free } \\
\hline 29.5 & 4.2761 & 26.6 & 17.2 & 0.799 & $11.4 \pm 0.8$ \\
\hline 38.4 & & 20.6 & & & \\
\hline 39.3 & 4.3233 & 17.8 & 26.4 & 0.904 & $20.7 \pm 1.6$ \\
\hline 49.0 & 4.3578 & 27.5 & 29.0 & & $24.4 \pm 1.8$ \\
\hline 53.4 & 4.3634 & 17.8 & 13.7 & & $33.3 \pm 4.3$ \\
\hline 55.9 & 4.3547 & 20.7 & 25.7 & 1.016 & $26.8 \pm 1.2$ \\
\hline 61.3 & 4.3483 & 14.4 & 34.8 & 1.065 & $26.8 \pm 2.7$ \\
\hline 65.1 & 4.3405 & 4.2 & 66.5 & 0.991 & $21.2 \pm 2.5$ \\
\hline \multicolumn{6}{|l|}{ Ni-doped } \\
\hline 28.8 & 4.3010 & 5.5 & 2.6 & 0.025 & $20.0 \pm 1.1$ \\
\hline 36.9 & 4.3391 & 8.8 & 14.2 & 0.248 & $19.0 \pm 1.9$ \\
\hline 39.4 & 4.3521 & 12.9 & 3.8 & 0.088 & $23.4 \pm 2.3$ \\
\hline 41.9 & 4.3601 & 21.8 & 13.3 & 0.562 & $29.1 \pm 3.1$ \\
\hline 46.3 & 4.3678 & 19.2 & 11.3 & 0.404 & $25.8 \pm 2.3$ \\
\hline 50.5 & 4.3411 & 23.4 & 32.9 & & $24.2 \pm 2.2$ \\
\hline 52.4 & 4.3472 & & & & \\
\hline 52.9 & & 20.1 & 14.3 & 0.556 & $23.9 \pm 2.6$ \\
\hline 56.5 & 4.3419 & 11.2 & 41.4 & & $30.6 \pm 1.8$ \\
\hline 57.5 & 4.3450 & 9.2 & 39.7 & & $29.9 \pm 2.0$ \\
\hline 57.8 & 4.3489 & 7.8 & 44.8 & & $22.6 \pm 3.5$ \\
\hline 64.4 & 4.3432 & 6.1 & 40.2 & 0.609 & $21.4 \pm 1.9$ \\
\hline 66.4 & 4.3229 & 4.1 & 54.8 & 0.688 & $27.5 \pm 2.3$ \\
\hline
\end{tabular}

TABLE 3: Overview of the coatings prepared by HiPIMS.

\begin{tabular}{|c|c|c|c|c|c|}
\hline $\mathrm{C}$ (at. \%) & Lattice parameter $(\AA)$ & Grain size (nm) & a-C:H phase (\%) & MGS (nm) & Hardness (GPa) \\
\hline \multicolumn{6}{|l|}{ Ni-free } \\
\hline 25.0 & 4.2502 & 36.5 & & & $15.1 \pm 1.3$ \\
\hline 40.0 & 4.2950 & 24.1 & 5.8 & 0.221 & $34.5 \pm 2.5$ \\
\hline 49.0 & 4.3180 & 27.9 & 14.1 & 0.671 & $38.3 \pm 2.7$ \\
\hline 53.0 & 4.3216 & 22.4 & 16.6 & 0.650 & $40.0 \pm 3.0$ \\
\hline 57.0 & 4.3130 & 10.0 & 25.2 & 0.483 & $44.7 \pm 3.8$ \\
\hline 68.0 & 4.2890 & 5.5 & 55.4 & 0.873 & $31.5 \pm 3.6$ \\
\hline \multicolumn{6}{|l|}{ Ni-doped } \\
\hline 22.9 & 4.2600 & 4.3 & 5.7 & 0.043 & $17.3 \pm 0.8$ \\
\hline 33.8 & 4.3033 & 5.5 & 8.6 & 0.084 & $26.8 \pm 2.1$ \\
\hline 36 & 4.3118 & 7.5 & & & $33.8 \pm 1.5$ \\
\hline 47.7 & 4.3185 & 15.5 & 12.1 & 0.341 & $38.2 \pm 4.1$ \\
\hline 50.7 & 4.3120 & 1.6 & 13.9 & 0.041 & $33.6 \pm 4.4$ \\
\hline 63 & 4.2982 & 3.0 & 37.0 & 0.264 & $24.6 \pm 4.1$ \\
\hline 77.2 & 4.2930 & 2.0 & 70.2 & 0.576 & $20.4 \pm 1.7$ \\
\hline
\end{tabular}

\section{Discussion}

The observed dependencies of the crystalline phase from XRD analyses (Figures 2-4) can be summarized and explained as follows. Only diffractions corresponding to fcc $\mathrm{TiC}$ lattice were observed (see Figure 2) for both $\mathrm{Ni}$-free and Ni-doped coatings. Thus, $\mathrm{Ni}$ did not form independent crystallites. It was incorporated in $\mathrm{TiC}$ grains or it was dispersed in the carbon matrix. As the lattice parameter of the Ni-doped coatings was influenced by $\mathrm{Ni}$ being always larger than that of the Ni-free coatings (Figure 3) the nickel incorporation in the grains can be presumed. The increase 


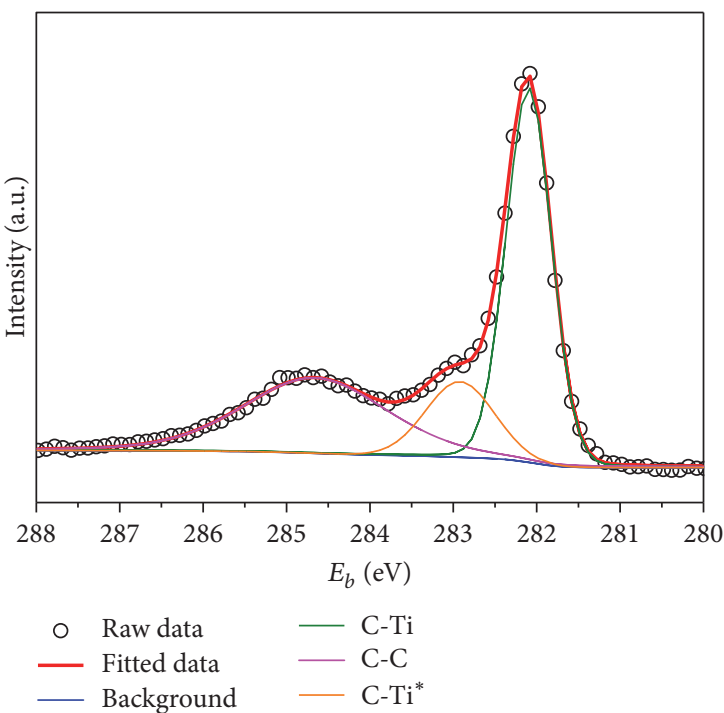

(a)

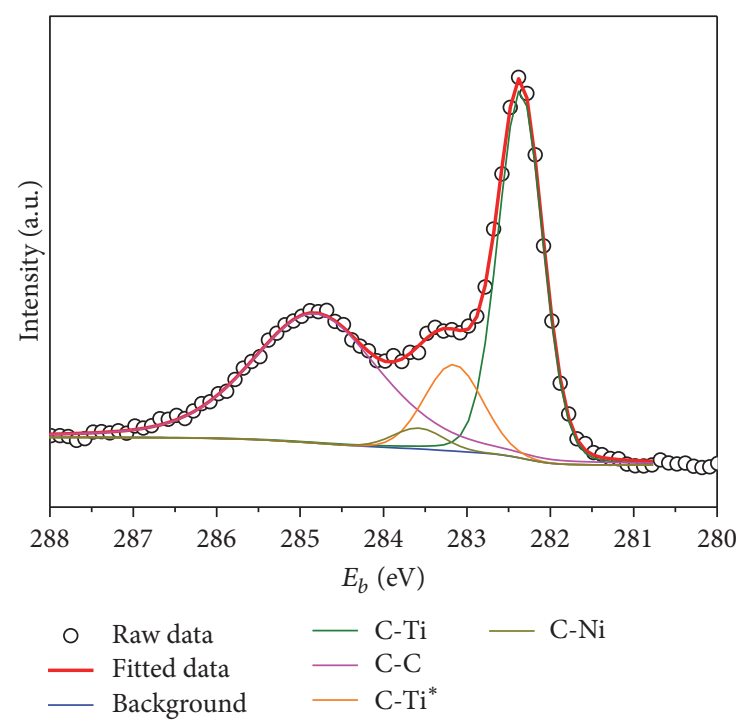

(b)

FIGURE 7: Fitted XPS spectra of C1s peak of (a) Ni-free coating and (b) Ni/doped coating with similar carbon content of $\sim 60 \%$.

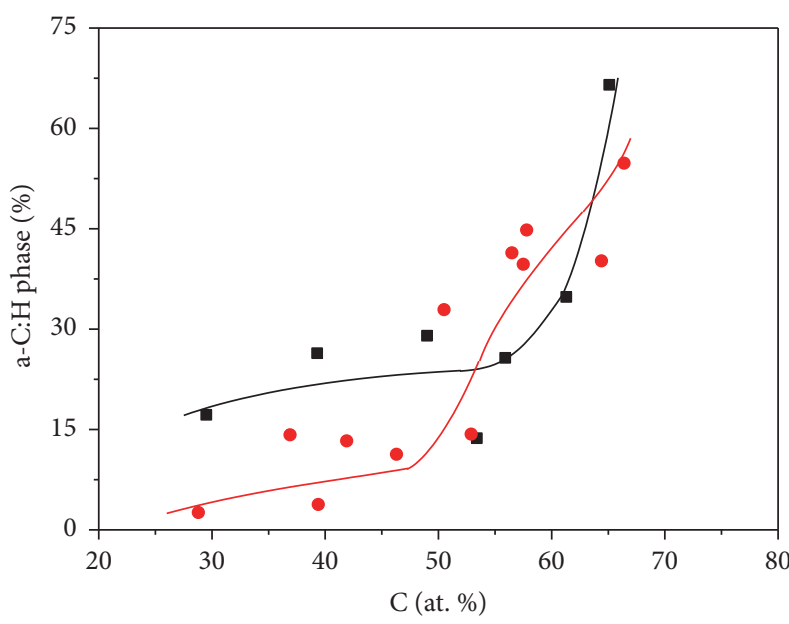

- Without $\mathrm{Ni}$

- With $\mathrm{Ni}$

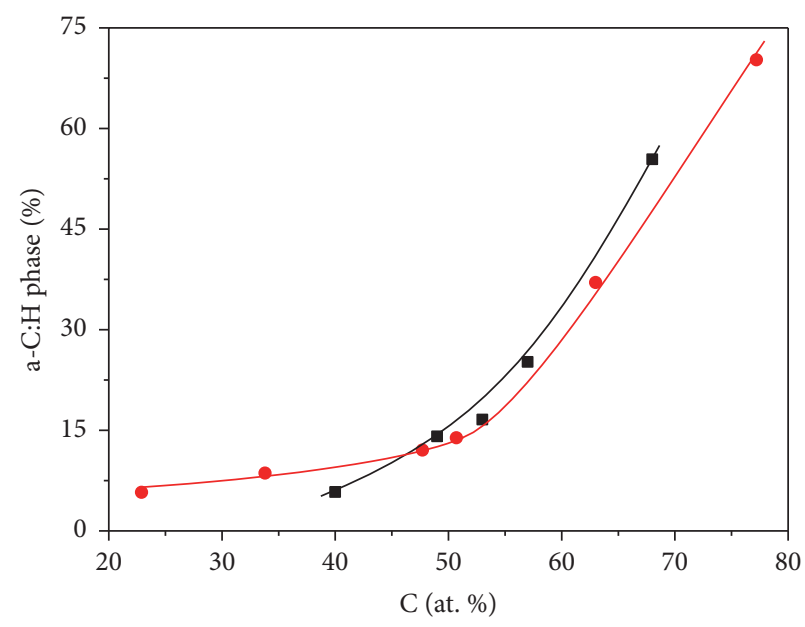

- Without $\mathrm{Ni}$

- With $\mathrm{Ni}$

(a)

(b)

Figure 8: The relative amount of the amorphous hydrogenated carbon (a-C:H) phase. Comparison of the Ni-free (black marks) and the Ni-doped (red marks) coatings prepared by (a) the DCMS and (b) the HiPIMS. Lines are added as guides for the eye.

of the lattice parameter of the coatings with increasing total carbon content in coatings with $\$ 50 \%$ can be explained by vacancy filling [34]. The number of vacancies in the $\mathrm{TiC}$ crystal lattice decreased with increasing carbon content. The carbon atoms occupied the vacancies and the lattice parameter increased accordingly. The DCMS prepared coatings with $\gtrsim 50 \%$ of carbon exhibited higher lattice parameter than bulk value [36]. Similar effect, that is, higher value of the lattice parameter of DCMS deposited TiC/C coatings than the bulk lattice parameter of $\mathrm{TiC}$, was observed by several authors $[3,26,39-41]$. The lattice parameter of the HiPIMS prepared coatings (Figure $3(\mathrm{~b})$ ) was always lower than the lattice parameter of the DCMS (Figure 3(a)) prepared coatings. This was due to the generally higher kinetic energy of the particles impinging the surface of the growing coatings in HiPIMS [42]. Higher energy influx promoted the surface diffusion of the adatoms and enabled them to reach energetically more favorable position. Higher energy influx and promoted surface diffusion resulted in denser crystallites as indicated by the lower lattice parameter in the HiPIMS case [29].

A decrease of the grain size with increasing carbon content was observed in DCMS as well as in HiPIMS prepared coatings with carbon content $\gtrsim 50 \%$ regardless of $\mathrm{Ni}$ doping. This is due to a rapid increase of the a-C:H 


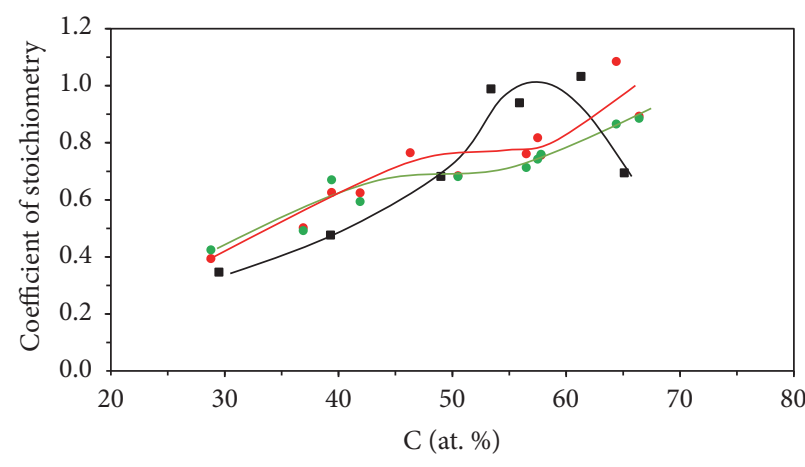

- Without Ni

- With $\mathrm{Ni}(\mathrm{C}-\mathrm{Ti})+(\mathrm{C}-\mathrm{Ni})$

- With $\mathrm{Ni}(\mathrm{C}-\mathrm{Ti})$

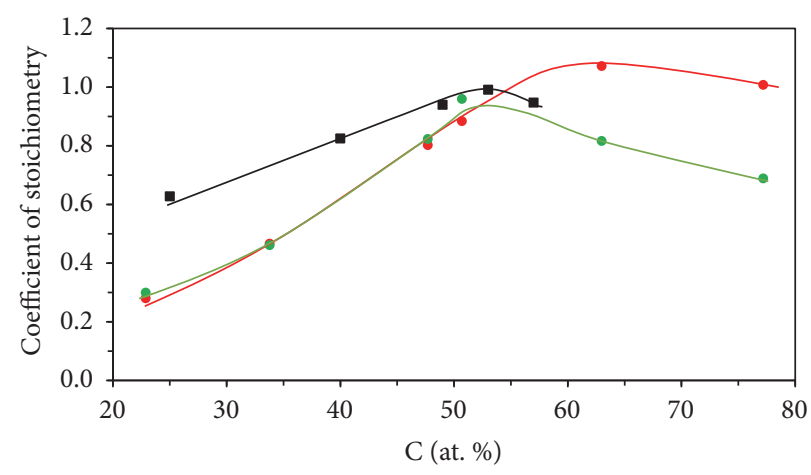

- Without Ni

- With $\mathrm{Ni}(\mathrm{C}-\mathrm{Ti})+(\mathrm{C}-\mathrm{Ni})$

- With $\mathrm{Ni}(\mathrm{C}-\mathrm{Ti})$

(a)

(b)

FIGURE 9: Stoichiometry in TiC crystallites of the Ni-free (black marks) and of the Ni-doped (red and green marks) coating. Comparison of (a) the DCMS and (b) the HiPIMS prepared sets of coatings. Lines are added as guides for the eye.

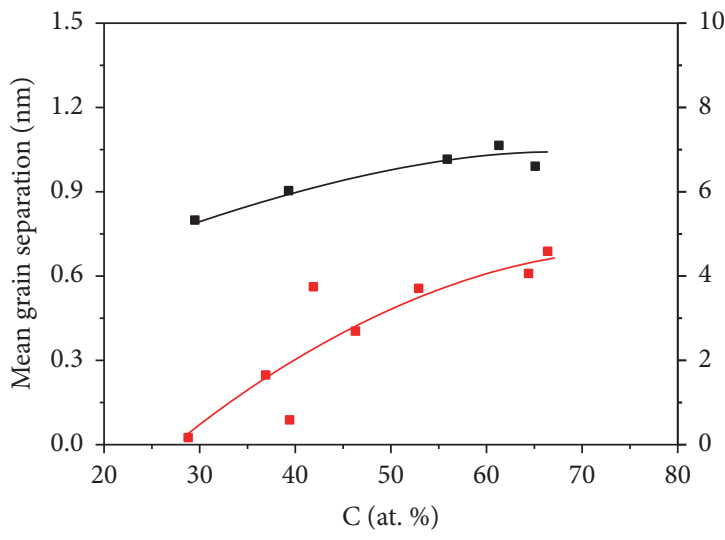

- Without Ni

- With Ni
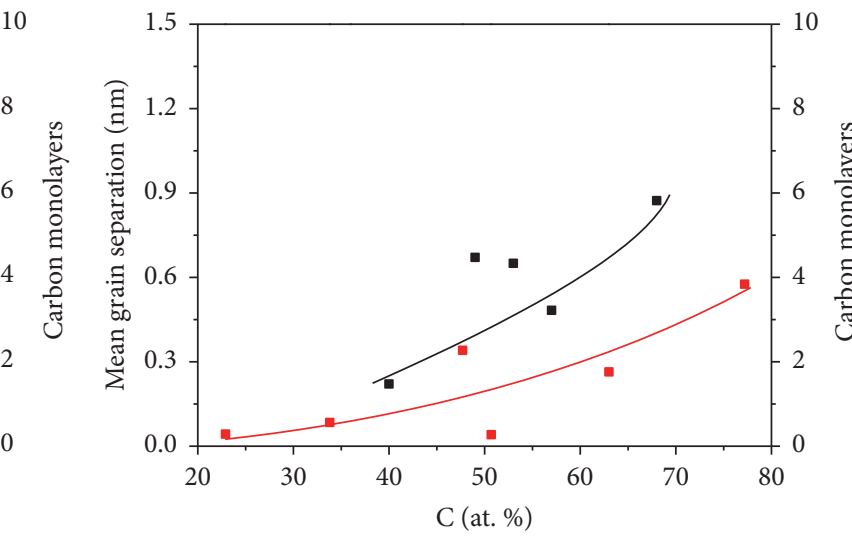

- Without $\mathrm{Ni}$

- With $\mathrm{Ni}$

(a)

(b)

FIGURE 10: The mean grain separation of the Ni-free (black marks) and of the Ni-doped (red marks) coating. Comparison of (a) the DCMS and (b) the HiPIMS prepared sets of coatings. Lines are added as guides for the eye.

phase content in coatings with carbon content $\gtrsim 50 \%$ (see Figure 5). Thus the a-C:H phase covered the growing grains and hindered their growth [29]. This led to formation of higher number of smaller grains. Ni-doped coatings with carbon content $\leqslant 50 \%$ exhibited smaller grains than the Nifree coatings with similar carbon content (see Figure 4). This effect was more pronounced in the coatings with low amount of carbon and high amount of nickel. A similar phenomenon of grain size decrease initiated by third-element doping was observed in other carbide systems [21, 37, 43, 44]. Råsander et. al. calculated that nickel presence in the TiC lattice leads to lowering of the formation energy and the migration energy barriers of the carbon vacancies in comparison with the Ni-free TiC lattice [45]. High concentration of crystal defects, for example, vacancies, leads to the formation of planar defects acting as grain boundaries which resulted in smaller grains compared to a system with lower number of vacancies [34]. Thus, we formulate a hypothesis that nickel incorporation into the nc-TiC/a-C:H coatings modified the vacancy distribution in the $\mathrm{TiC}_{x}$ grains which resulted in arrangement of planar defects leading to formation of grain boundaries and thus to the reduction of the grain size.

Jansson et al. [22] proposed that Ni addition should lead to releasing of the carbon from the $\mathrm{TiC}$ grains into the a$\mathrm{C}$ phase. Thus, Ni-doped coatings with the same amount of carbon as Ni-free coatings should exhibit a higher amount of a-C phase. However, in our study, no influence of nickel addition on the amount of amorphous carbon phase was observed for the HiPIMS prepared coatings (see Figure 6(b)). In the case of the DCMS prepared coatings, the Ni-doped coatings with $\leqslant 50 \%$ of carbon exhibited even lower amount of the a-C(:H) phase than the Ni-free coatings (Figure 8(a)).

It has been observed that the a-C(:H) phase was formed even for coatings with $\$ 50 \%$ of carbon $[10,16]$. So the 


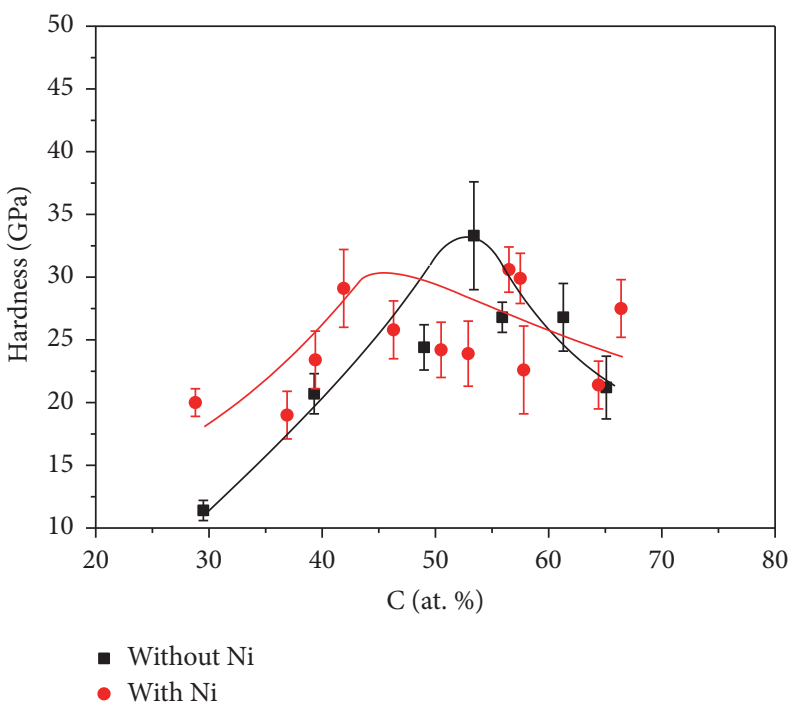

(a)

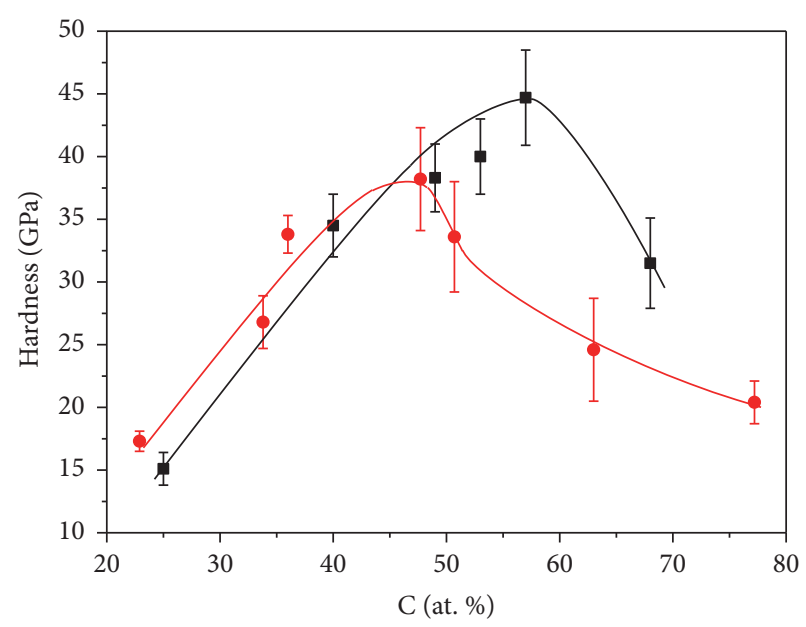

- Without $\mathrm{Ni}$

- With $\mathrm{Ni}$

(b)

FIGURE 11: The hardness of the Ni-free (black marks) and the Ni-doped (red marks) coatings. Comparison of (a) the DCMS and (b) the HiPIMS prepared coatings. Lines are added as guides for the eye.

coatings are composed of $\mathrm{TiC}$ grains with strong deficit of carbon surrounded by small amount of amorphous carbon. High temperature or strong ion bombardment may force the carbon to pass from the a-C:H phase near the grain surface to the grain itself. The Ni-doped coatings with $\leqslant 50 \%$ C prepared by DCMS exhibited significantly smaller grains (see Figure 4(a)) and lower amount of the a-C:H phase (see Figure 8(a)) than the corresponding Ni-free coatings. The lower amount of the a-C:H phase in case of the Nidoped coatings can be explained by presence of smaller grains with higher surface/volume ratio, facilitating the effect of the carbon transfer from the matrix to the grains. In the case of HiPIMS the ion bombardment was so intense that enough energy is supplied where carbon was incorporated into the grains independently of their size. The nickel induced grain size reduction thus did not significantly affect the amount of the a-C:H phase in HiPIMS deposited coatings. Furthermore, in strongly substoichiometric TiC grains the nickel addition may not lead to complete releasing of carbon atoms from a grain, but rather to carbon atom relocation within a $\mathrm{TiC}$ grain. The carbon atom could be trapped in a nearby vacancy instead of being removed from the grain to the amorphous phase.

The evolution of the mean grain size and the mean grain separation of the Ni-free and the Ni-doped coatings prepared by DCMS is schematically depicted in Figure 12. Analogous scheme for the HiPIMS prepared coatings is depicted in Figure 13. For simplicity, we can divide all the range of carbon content into three zones. This division into three zones illustrates the changes of the microstructure of the deposited coatings affecting the mechanical properties.

In the case of the DCMS deposited coatings an increase of the hardness was observed up to carbon content of $~ 50 \%$ (Zone 1 in Figures 12(a) and 12(b)). This increase was

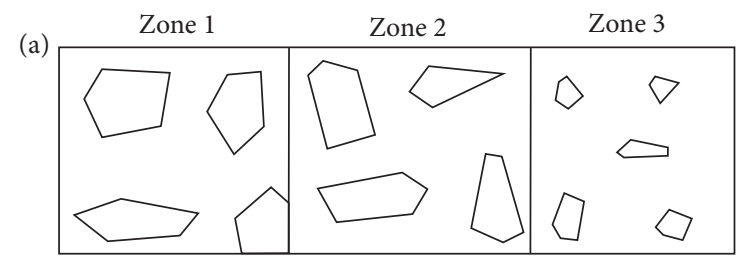

(b)
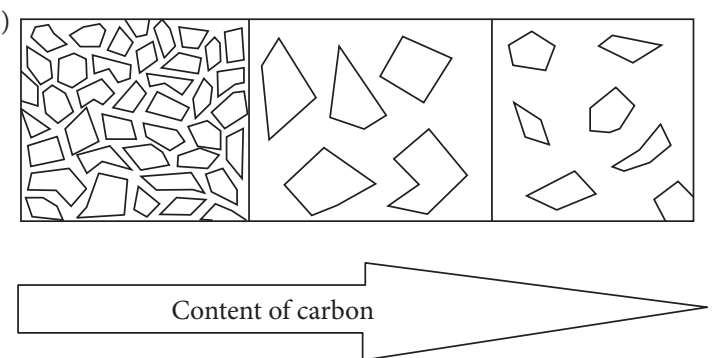

FIGURE 12: Scheme of the mean grain size and the mean grain separation of (a) the Ni-free and (b) the Ni-doped coatings prepared by DCMS. Zone 1 denoted coatings with low amount of carbon, Zone 2 denoted medium amount of carbon, and Zone 3 denoted high amount of carbon.

attributed to lowering of the grain vacancy concentration similarly to [26], because only low vacancy concentration is favorable for achieving a high hardness [46, 47]. Increase of the initially low grain size in the case of the $\mathrm{Ni}$-doped coatings was also an important factor in the hardness enhancement because of effects analogical to the Hall-Petch effect [4853]. The initial hardness increase with increasing carbon content was observed despite a slight increase of the MGS as high MGS facilitates the grain sliding [54]. The DCMS prepared Ni-doped coatings with carbon content $\leqslant 50 \%$ also 
(a)

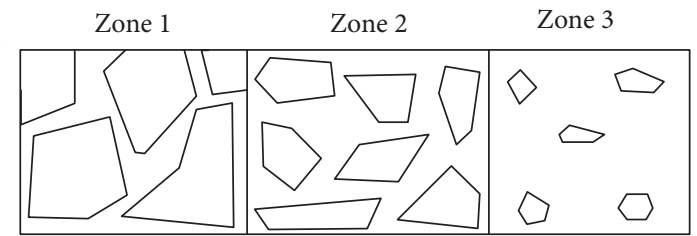

(b)

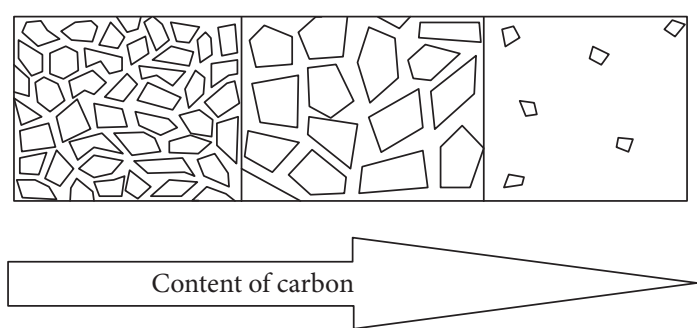

FIgURE 13: Scheme of the mean grain size and the mean grain separation of (a) the Ni-free and (b) the Ni-doped coatings prepared by HiPIMS. Zone 1 denoted coatings with low amount of carbon, Zone 2 denoted medium amount of carbon, and Zone 3 denoted high amount of carbon.

exhibited higher hardness than the Ni-free coatings. This hardening was attributed to lower grain size as well as the lower amount of a-C:H phase corresponding to lower MGS. Also the Ni-doped coatings exhibited lower amount of the a-C:H phase for the same total carbon content and thus lower carbon vacancy concentration in the grains can be expected. The hardness of the DCMS deposited coatings with carbon content $\gtrsim 50 \%$ was similar for the $\mathrm{Ni}$-doped and the $\mathrm{Ni}$-free coatings due to comparable grain size as well as comparable amount of the a-C:H phase (see Zone 3 in Figures 11(a) and 11(b)). Some slight differences in the grain size and in the a$\mathrm{C}: \mathrm{H}$ phase content led to differences in the MGS; however, generally high MGS ( $\gg 1$ monolayer) had no appreciable effect on the measured hardness as only 1 monolayer is optimal for the effect of nanocomposite hardening $[51,52,55]$.

The coating microstructure governed also the hardness of the coatings prepared by HiPIMS. The initial hardness increase up to $50 \%$ of carbon was mainly caused by lowering of the grain vacancy concentration and the grain size evolution (Zone 1 in Figure 13). The initial TiC grain size of $\sim 5 \mathrm{~nm}$ observed in the Ni-doped coatings was low and the effect analogical to the inverse Hall-Petch effect in polycrystalline films could occur [51-53, 55]. As the TiC grain size increased, the hardness increased accordingly. The maximum grain size of $\sim 15 \mathrm{~nm}$ was reached at $45 \%$ of carbon (Zone 2 in Figure 13). The grains still contained lattice vacancies because of carbon deficiency and preferential formation of the a-C:H matrix phase. The individual grains were on average separated by $\sim 2$ monolayers of the matrix. This combination of parameters resulted in hardness of $\sim 37 \mathrm{GPa}$. On the other hand, the Nifree coatings initially exhibited large grains with the size of $\sim 35 \mathrm{~nm}$ that is too high for achieving high hardness due the effect analogous to the Hall-Petch effect in polycrystallites [51-53]. The grain size steadily decreased while the hardness increased with the carbon content increase (see Zone 3 in Figures 13(a) and 13(b)). The combination of the grain size, low vacancy concentration, and low mean grain separation which was optimal for the highest hardness was reached in coating with $\sim 55 \%$ of $C$. This coating exhibited $\sim 10 \mathrm{~nm}$ grains separated by $\sim 3$ monolayers of the matrix. Low vacancy concentration can be expected as the carbon content is $>50 \%$ unlike in the case of the hardest $\mathrm{Ni}$-doped coating. This combination of parameters resulted in maximal hardness of $\sim 45 \mathrm{GPa}$.

The hardness of the coatings deposited by HiPIMS was generally higher than that of the corresponding DCMS deposited coatings. This can be partially attributed to grain size decrease, but also to the lower amount of the a-C:H phase formed under HiPIMS conditions. This led to a lower mean grain separation as well as reduction of grain vacancy concentration in the grains due to HiPIMS induced carbon transfer from the matrix to the grains.

\section{Conclusion}

$\mathrm{Ni}$-free and Ni-doped nc-TiC/a-C:H coatings were prepared by a hybrid PVD-PECVD process of titanium and titaniumnickel compound target sputtering in argon/acetylene atmosphere. DCMS as well as the HiPIMS was used for the depositions in order to study the influence of the plasma excitation on the structure and hardness of the deposited coatings.

Nickel was found to be incorporated into the grains. Nickel addition also led to decrease of the grain size. This effect was more pronounced for the coatings with carbon content $\lesssim 50 \%$. The grain size reduction was attributed to grain boundary formation due to formation of lattice defects induced by nickel incorporation into the grains. Smaller grains in the $\mathrm{Ni}$-doped coatings prepared by DCMS exhibited higher surface to volume ratio than that exhibited by the larger grains in the $\mathrm{Ni}$-free coatings. This led to decrease of the amount of the a-C:H phase in the Ni-free coatings as higher surface area of the grains led to enhanced carbon transfer from the matrix to the grains. The HiPIMS prepared coatings exhibited no influence of nickel addition on the a-C:H amount, due the high ion bombardment energy promoting the carbon incorporation even into the bulk of the larger grains. The resulting hardness of the deposited coatings was shown to be governed primarily by the grain size, vacancy concentration in the grains, and their mean grain separation. Ni doping had a significant effect on the hardness of the coatings. For DCMS deposited coatings with $\leqslant 50 \%$ of carbon the hardness increased with $\mathrm{Ni}$ doping due to favorable structure changes. The structure was not significantly changed and the hardness was not changed. The effect of the Ni doping was less pronounced for HiPIMS deposited coatings with $\lesssim 50 \%$ of carbon. However, the hardness of the Ni-doped coatings was strongly reduced for coatings with higher carbon content primarily due to unfavorable grain size lowering induced by Ni doping.

\section{Conflicts of Interest}

The authors declare that they have no conflicts of interest. 


\section{Acknowledgments}

This research has been supported by Project LO1411 (NPU I) funded by Ministry of Education, Youth and Sports of Czech Republic and the Czech Science Foundation (Project 15-17875S).

\section{References}

[1] J.-E. Sundgren, B.-O. Johansson, and S.-E. Karlsson, "Mechanisms of reactive sputtering of titanium nitride and titanium carbide I: influence of process parameters on film composition," Thin Solid Films, vol. 105, no. 4, pp. 353-366, 1983.

[2] D. Martínez-Martínez, C. López-Cartes, A. Fernández, and J. C. Sánchez-López, "Influence of the microstructure on the mechanical and tribological behavior of TiC/a-C nanocomposite coatings," Thin Solid Films, vol. 517, no. 5, pp. 1662-1671, 2009.

[3] T.Zehnder and J. Patscheider, "Nanocomposite TiC/a-C:H hard coatings deposited by reactive PVD," Surface and Coatings Technology, vol. 133, no. 134, pp. 138-144, 2000.

[4] Pavel Souček, T. Schmidtová, L. Zábranský et al., "On the control of deposition process for enhanced mechanical properties of nc-TiC/a-C:H coatings with DC magnetron sputtering at low or high ion flux," Surface and Coatings Technology, vol. 255, pp. 8-14, 2014.

[5] Y. T. Pei, D. Galvan, J. T. M. De Hosson, and A. Cavaleiro, "Nanostructured TiC/a-C coatings for low friction and wear resistant applications," Surface and Coatings Technology, vol. 198, no. 1-3, pp. 44-50, 2005.

[6] D. Galvan, Y. T. Pei, and J. T. M. De Hosson, "TEM characterization of a $\mathrm{Cr} / \mathrm{Ti} / \mathrm{TiC}$ graded interlayer for magnetron-sputtered TiC/a-C:H nanocomposite coatings," Acta Materialia, vol. 53, no. 14, pp. 3925-3934, 2005.

[7] Y. Wang, X. Zhang, X. Wu, H. Zhang, and X. Zhang, "Compositional, structural and mechanical characteristics of nc-TiC/aC:H nanocomposite films," Applied Surface Science, vol. 255, no. 5, pp. 1801-1805, 2008.

[8] W. K. Chu, J. W. Mayer, and M. A. Nicolet, Back Scattering Spectrometry, Academic Press, New York, NY, USA, 1978.

[9] U. Wiklund, M. Nordin, O. Wänstrand, and M. Larsson, "Evaluation of a flexible physical vapor deposited TiC-C coating system," Surface and Coatings Technology, vol. 124, no. 2-3, pp. 154-161, 2000.

[10] Y. Hu, L. Li, X. Cai, Q. Chen, and P. K. Chu, "Mechanical and tribological properties of TiC/amorphous hydrogenated carbon composite coatings fabricated by DC magnetron sputtering with and without sample bias," Diamond and Related Materials, vol. 16, no. 1, pp. 181-186, 2007.

[11] W. J. Meng, R. C. Tittsworth, and L. E. Rehn, "Mechanical properties and microstructure of TiC/amorphous hydrocarbon nanocomposite coatings," Thin Solid Films, vol. 377-378, pp. 222-232, 2000.

[12] T. Zehnder, P. Schwaller, F. Munnik, S. Mikhailov, and J. Patscheider, "Nanostructural and mechanical properties of nanocomposite nc-TiC/a-C:H films deposited by reactive unbalanced magnetron sputtering," Journal of Applied Physics, vol. 95, no. 8, pp. 4327-4334, 2004.

[13] S. Zhang, X. L. Bui, J. Jiang, and X. Li, "Microstructure and tribological properties of magnetron sputtered $\mathrm{nc}-\mathrm{TiC} / \mathrm{a}-\mathrm{C}$ nanocomposite," Surface and Coatings Technology, vol. 198, no. 1-3, pp. 206-211, 2005.
[14] G. Li and L. F. Xia, "Structural characterization of $\mathrm{TiC}_{x}$ films prepared by plasma based ion implantation," Thin Solid Films, vol. 396, no. 1-2, pp. 16-22, 2001.

[15] E. Lewin, P. O. Å. Persson, M. Lattemann et al., "On the origin of a third spectral component of C1s XPS-spectra for nc-TiC/aC nanocomposite thin films," Surface and Coatings Technology, vol. 202, no. 15, pp. 3563-3570, 2008.

[16] D. M. Cao, B. Feng, W. J. Meng, L. E. Rehn, P. M. Baldo, and M. M. Khonsari, "Friction and wear characteristics of ceramic nanocomposite coatings: Titanium carbide/amorphous hydrocarbon," Applied Physics Letters, vol. 79, no. 3, pp. 329-331, 2001.

[17] J. C. Sánchez-López, D. Martínez-Martínez, C. López-Cartes, C. Fernández-Ramos, and A. Fernández, "A nanoscale approach for the characterization of amorphous carbon-based lubricant coatings," Surface and Coatings Technology, vol. 200, no. 1-4, pp. 40-45, 2005.

[18] J. Musil, P. Novák, R. Čerstvý, and Z. Soukup, “Tribological and mechanical properties of nanocrystalline-TiC/a-C nanocomposite thin films," Journal of Vacuum Science \& Technology A, vol. 28, no. 2, pp. 244-249, 2010.

[19] Y. T. Pei, D. Galvan, J. T. M. De Hosson, and C. Strondl, "Advanced TiC/a-C:H nanocomposite coatings deposited by magnetron sputtering," Journal of the European Ceramic Society, vol. 26, no. 4-5, pp. 565-570, 2006.

[20] T. Schmidtová, P. Souček, V. Kudrle, and P. Vašina, "Nonmonotonous evolution of hybrid PVD-PECVD process characteristics on hydrocarbon supply," Surface and Coatings Technology, vol. 232, pp. 283-289, 2013.

[21] U. Jansson and E. Lewin, "Sputter deposition of transition-metal carbide films-a critical review from a chemical perspective," Thin Solid Films, vol. 536, pp. 1-24, 2013.

[22] U. Jansson, E. Lewin, M. Råsander, O. Eriksson, B. André, and U. Wiklund, "Design of carbide-based nanocomposite thin films by selective alloying," Surface and Coatings Technology, vol. 206, no. 4, pp. 583-590, 2011.

[23] R. Žemlička, M. Jílek, P. Vogl et al., "Understanding of hybrid PVD-PECVD process with the aim of growing hard nc-TiC/a$\mathrm{C}$ : H COATINGS using industrial devices with a rotating cylindrical magnetron," Surface and Coatings Technology, vol. 255, pp. 118-123, 2014.

[24] P. Souček, T. Schmidtová, L. Zábranský et al., "Evaluation of composition, mechanical properties and structure of nc-TiC/a$\mathrm{C}: \mathrm{H}$ coatings prepared by balanced magnetron sputtering," Surface and Coatings Technology, vol. 211, pp. 111-116, 2012.

[25] P. Souček, T. Schmidtová, V. Buršíková et al., “Tribological properties of nc-TiC/a-C: $\mathrm{H}$ coatings prepared by magnetron sputtering at low and high ion bombardment of the growing film," Surface and Coatings Technology, vol. 241, pp. 64-73, 2014.

[26] P. Souček, J. Daniel, J. Hnilica et al., "Superhard nanocomposite nc-TiC/a-C:H coatings: the effect of HiPIMS on coating microstructure and mechanical properties," Surface and Coatings Technology, vol. 311, pp. 257-267, 2017.

[27] U. Helmersson, M. Lattemann, J. Bohlmark, A. P. Ehiasarian, and J. T. Gudmundsson, "Ionized physical vapor deposition (IPVD): a review of technology and applications," Thin Solid Films, vol. 513, no. 1-2, pp. 1-24, 2006.

[28] K. Sarakinos, J. Alami, and S. Konstantinidis, "High power pulsed magnetron sputtering: a review on scientific and engineering state of the art," Surface and Coatings Technology, vol. 204, no. 11, pp. 1661-1684, 2010.

[29] M. Samuelsson, D. Lundin, J. Jensen, M. A. Raadu, J. T. Gudmundsson, and U. Helmersson, "On the film density using high 
power impulse magnetron sputtering," Surface and Coatings Technology, vol. 205, no. 2, pp. 591-596, 2010.

[30] P. Scherrer, "Estimation of the size and internal structure of colloidal particles by means of röntgen," Nachrichten von der Gesellschaft der Wissenschaften zu Göttingen, vol. 2, pp. 96-100, 1918.

[31] W. C. Oliver and G. M. Pharr, "Measurement of hardness and elastic modulus by instrumented indentation: advances in understanding and refinements to methodology," Journal of Materials Research, vol. 19, no. 1, pp. 3-20, 2004.

[32] K. L. Johnson, "The correlation of indentation experiments," Journal of the Mechanics and Physics of Solids, vol. 18, no. 2, pp. $115-126,1970$.

[33] N. N. Greenwood and A. Earnshaw, Chemistry of the Elements, Elsevier, 2012.

[34] A. I. Gusev, A. A. Rempel, A. Magerl, and J., Disorder and Order in Strongly Nonstoichiometric Compounds: Transition Metal Carbides, Nitrides and Oxides, vol. 47, Springer Science \& Business Media, 2013.

[35] J. Vlček, P. Kudláček, K. Burcalová, and J. Musil, “High-power pulsed sputtering using a magnetron with enhanced plasma confinement," Journal of Vacuum Science and Technology A: Vacuum, Surfaces and Films, vol. 25, no. 1, pp. 42-47, 2007.

[36] L. Toth, Ed., Transition Metal Carbides and Nitrides, Elsevier, 2014.

[37] E. Lewin, B. André, S. Urbonaite, U. Wiklund, and U. Jansson, "Synthesis, structure and properties of Ni-alloyed $\mathrm{TiC}_{x}$-based thin films," Journal of Materials Chemistry, vol. 20, no. 28, pp. 5950-5960, 2010.

[38] J. Robertson, "Diamond-like amorphous carbon," Materials Science and Engineering: R: Reports, vol. 37, pp. 129-282, 2002.

[39] E. Lewin, M. Rsander, M. Klintenberg, A. Bergman, O. Eriksson, and U. Jansson, "Design of the lattice parameter of embedded nanoparticles," Chemical Physics Letters, vol. 496, no. 1-3, pp. 95-99, 2010.

[40] E. Lewin, O. Wilhelmsson, and U. Jansson, "Nanocomposite ncTiC/a-C thin films for electrical contact applications," Journal of Applied Physics, vol. 100, no. 5, Article ID 054303, 2006.

[41] E. Lewin, M. Gorgoi, F. Schäfers, S. Svensson, and U. Jansson, "Influence of sputter damage on the XPS analysis of metastable nanocomposite coatings," Surface and Coatings Technology, vol. 204, no. 4, pp. 455-462, 2009.

[42] D. Binder and W. J. Sturm, "Equivalence of X-ray lattice parameter and density changes in neutron-irradiated LiF," Physical Review, vol. 96, no. 6, pp. 1519-1522, 1954.

[43] O. Wilhelmsson, S. Bijelovic, M. Lindquist et al., "Deposition and characterization of magnetic Ti-Fe-C nanocomposite thin films," Thin Solid Films, vol. 518, no. 10, pp. 2607-2616, 2010.

[44] E. Lewin, K. Buchholt, J. Lu, L. Hultman, A. L. Spetz, and U. Jansson, "Carbide and nanocomposite thin films in the Ti-Pt-C system," Thin Solid Films, vol. 518, no. 18, pp. 5104-5109, 2010.

[45] M. Råsander, B. Sanyal, U. Jansson, and O. Eriksson, "A first principles study of the stability and mobility of defects in titanium carbide," 2013, https://arxiv.org/abs/1303.2848.

[46] H. W. Hugosson, P. Korzhavyi, U. Jansson, B. Johansson, and O. Eriksson, "Phase stabilities and structural relaxations in substoichiometric $\mathrm{TiC}_{1-x}$," Physical Review B, vol. 63, no. 16, 2001.

[47] X.-X. Yu, G. B. Thompson, and C. R. Weinberger, "Influence of carbon vacancy formation on the elastic constants and hardening mechanisms in transition metal carbides," Journal of the European Ceramic Society, vol. 35, no. 1, pp. 95-103, 2015.
[48] J. Musil, "Hard nanocomposite coatings: thermal stability, oxidation resistance and toughness," Surface and Coatings Technology, vol. 207, pp. 50-65, 2012.

[49] E. O. Hall, "The deformation and ageing of mild steel: III discussion of results," Proceedings of the Physical Society Section $B$, vol. 64, no. 9, pp. 747-752, 1951.

[50] N. J. Petch, "The cleavage strength of polycrystals," Journal of the Iron and Steel Institute, vol. 174, pp. 25-28, 1953.

[51] S. Zhang, H. L. Wang, S.-E. Ong, D. Sun, and X. L. Bui, "Hard yet tough nanocomposite coatings-present status and future trends," Plasma Processes and Polymers, vol. 4, no. 3, pp. 219228, 2007.

[52] S. Vepřek and S. Reiprich, "A concept for the design of novel superhard coatings," Journal of Thin Solid Films, vol. 268, no. 12, pp. 64-71, 1995.

[53] J. Musil and J. Vlček, "Magnetron sputtering of hard nanocomposite coatings and their properties," Surface and Coatings Technology, vol. 142-144, pp. 557-566, 2001.

[54] J. Schiøtz, F. D. Di Tolla, and K. W. Jacobsen, "Softening of nanocrystalline metals at very small grain sizes," Nature, vol. 391, no. 6667, pp. 561-563, 1998.

[55] C. E. Carlton and P. J. Ferreira, "What is behind the inverse HallPetch effect in nanocrystalline materials?" Acta Materialia, vol. 55, no. 11, pp. 3749-3756, 2007. 

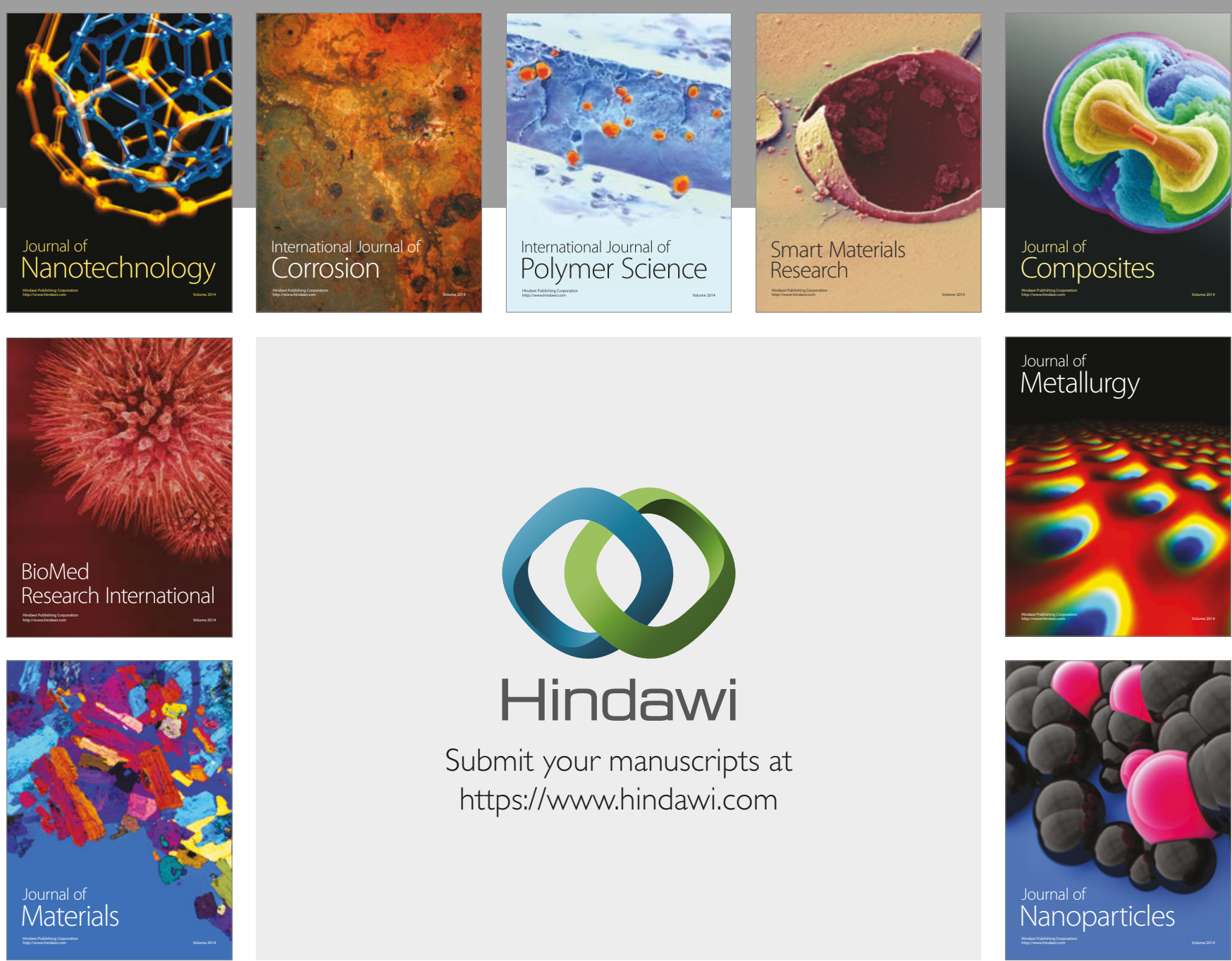

\section{Hindawi}

Submit your manuscripts at

https://www.hindawi.com
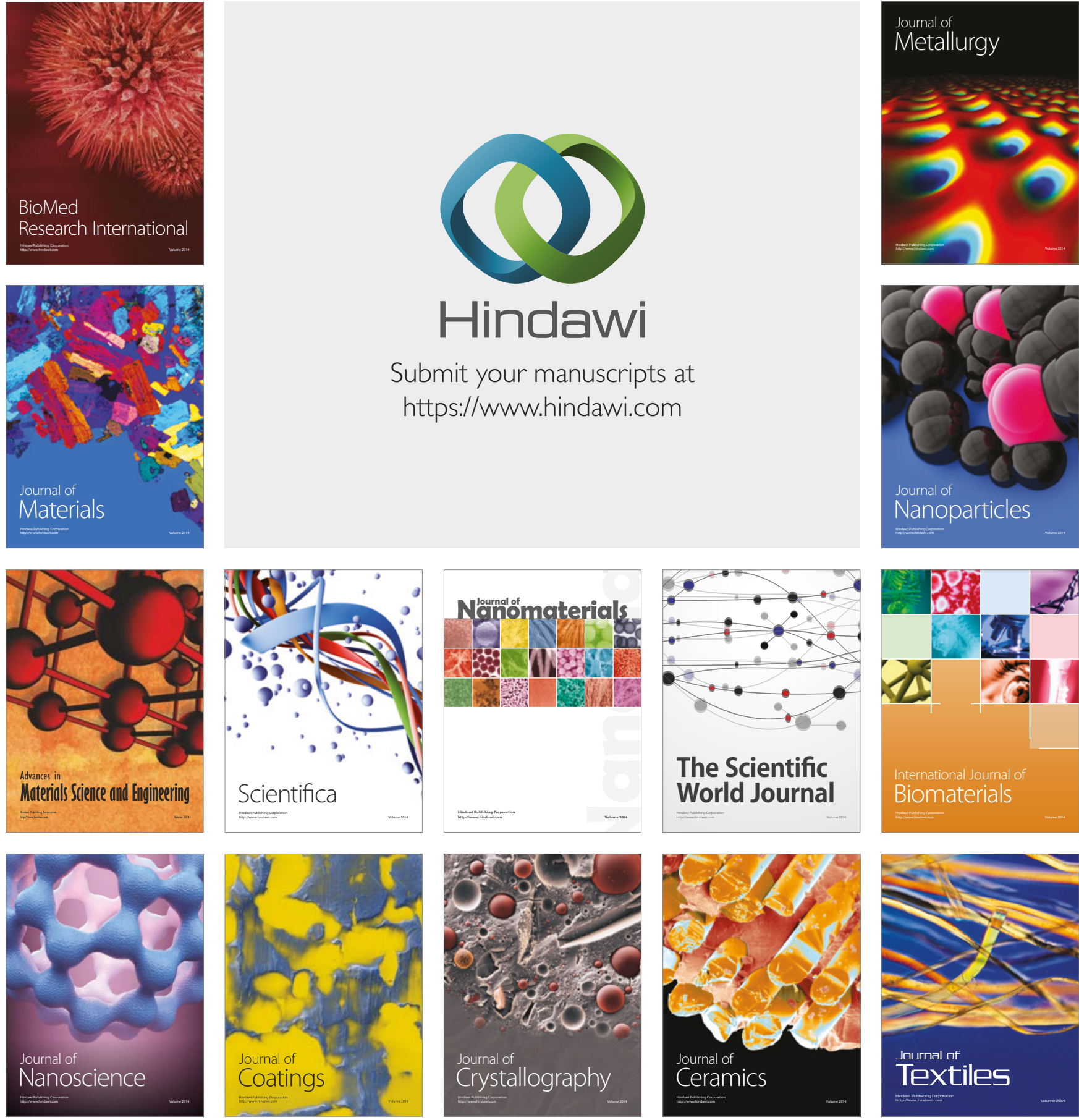

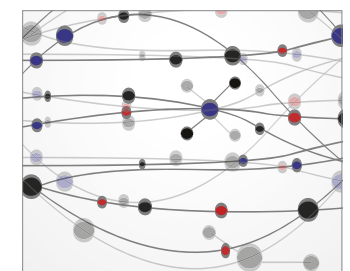

The Scientific World Journal
